\title{
Educação continuada em catalogação descritiva: um olhar emergente
}

\author{
Fabiano Ferreira de Castro \\ Universidade Federal de São Carlos - UFSCar, Brasil. \\ Sandra Vieira Santos \\ Universidade Federal de Sergipe - UFS, Brasil.
}

ARTIGOS / ARTICLE

\section{Resumo}

Objetivo.Verificar a importância da Educação Continuada na Catalogação Descritiva, seus benefícios para o bibliotecário e sua influência na qualidade do Tratamento Descritivo da Informação (TDI).

Método.Caracteriza-se por ser descritiva e exploratória, a fim de buscar conhecimento teórico e empírico acerca do tema, utilizando-se da aplicação de questionário e o levantamento documental, para identificar e caracterizar o perfil do bibliotecário sergipano e suas necessidades de educação continuada.

Resultados.Evidenciou que os bibliotecários e os órgãos de classe não reconhecem de forma efetiva a necessidade da Educação Continuada na Catalogação Descritiva, o que nos levou a definir que se faz necessária a união das organizações, dos órgãos de classe e das instituições de ensino, na criação de medidas que visem à promoção e à participação nesse processo. Conclusões.Recomenda-se a proposta de criação e de desenvolvimento de um curso lato sensu que sustente e promova ações efetivas para a educação continuada dos bibliotecários no estado de Sergipe.

\section{Palavras-chave}

Catalogação descritiva ; Educação continuada do bibliotecário ; Bibliotecas universitárias; Informação e tecnologia

\section{Continued education in descriptive cataloging: an emerging view}

\section{Abstract}

Objective. The research seeks to study the Continued Education in Descriptive Cataloging in Sergipe, in a window of ten years on the field of both private and public university libraries, with the aim at verifying the importance of Continued Education on Cataloging, its benefits to librarian and influences over the Descriptive Treatment of Information (DTI) quality.

Method.Characterized for being descriptive and explanatory, in order to seek for theoretical and empirical knowledge about the theme, running a questioner and documental making, to identify and make a profile of the librarian from Sergipe and its needs of continued education.

Results.Swed that the librarians and class organizations do not recognize in an effective way the need of continued education on descriptive cataloging, which took us to define that is necessary the union of the organizations, and educational institutions, on creating legislations that seek the participation on this process.

Conclusions.Recommended the proposal on creation and development of a latu sensu course that support and promote the effective actions for the continued education of the librarians in the State of Sergipe.

\section{Keywords}

Descriptive cataloging ; Continued education of librarians ; University libraries ; Information and technology 


\section{Introdução}

O fluxo crescente da produção bibliográfica faz a sociedade buscar por uma informação filtrada e de acesso rápido. Essa tendência afeta, sobretudo, aos ambientes informacionais representados pelas bibliotecas, que responsáveis por permitir esse acesso procuram readaptar seus espaços, no intuito de prestar um melhor serviço que atenda as necessidades dos usuários.

A Catalogação Descritiva ${ }^{1}$ ou Representação Descritiva, nesse contexto, desde os primeiros resquícios de necessidade de recuperação de informação, visa à codificação dos dados sobre a forma e o conteúdo dos recursos informacionais, para a recuperação da informação pelo usuário; por meio de padrões internacionais são estabelecidas as regras no desenvolvimento da catalogação, sendo aperfeiçoadas conforme a inserção de novas tecnologias e novos formatos para o armazenamento dos dados bibliográficos e catalográficos.

O bibliotecário enquanto profissional responsável por exercer essa atividade deve estar atento para acompanhar as atualizações da catalogação, e a Educação Continuada, na modalidade de eventos, pesquisas, reuniões associativo, ou cursos de atualização, dentre outras, é uma boa alternativa, pois possibilita ao profissional manter-se atualizado e melhorar a qualidade na realização da representação descritiva da informação. Diante do exposto o presente artigo retrata a importância da educação continuada do bibliotecário na área da Catalogação Descritiva desenvolvida pelos bibliotecários nas bibliotecas universitárias em Sergipe, verificando, os benefícios para o bibliotecário e sua influência na qualidade do Tratamento Descritivo da Informação (TDI).

Definiu-se uma metodologia caracterizada por ser de análise exploratória e descritiva, os procedimentos metodológicos são compostos pela pesquisa bibliográfica e documental com dados captados através de questionários, e documentos divulgados pelos órgãos de classe de Sergipe em ações de educação continuada nos últimos dez anos, como forma de análise optou-se pelo meio qualitativo. Esse estudo resultou na constatação de que os bibliotecários em Sergipe reconhecem a necessidade de especialização na catalogação, no entanto realiza de forma tímida essa atividade, agravando-se pelo fato da ausência de promoção nessa temática pelos órgãos de classe no estado.

A pesquisa vem com o intuito de contribuir com reflexões teóricas e práticas trazendo aos bibliotecários a importância do aprendizado contínuo da Catalogação Descritiva, destacando como as TIC2 influenciam na representação e na descrição de recursos informacionais, inserindo o estado de Sergipe nas ações vislumbradas pelas áreas da Biblioteconomia e Ciência da Informação.

Para melhor compreensão esse estudo está sistematizado: a seção 2 aborda uma visão histórica e conceitual do processo de catalogação, a seção 3 discorre sobre a atuação das bibliotecas universitárias no universo das tecnologias e a importância da Educação Continuada nesse contexto, a seção 4 percorre sobre os meios de promoção à Educação Continuada do bibliotecário, a seção 5 apresenta os resultados da pesquisa com algumas recomendações, e por fim as considerações finais onde são apresentadas as análises e as reflexões acerca da Educação Continuada em Catalogação Descritiva.

\section{A catalogação descritiva revisitada: um olhar emergente à partir de suas correntes teóricas à sua práxis}

As bibliotecas são ambientes que sempre se preocuparam com a preservação da massa documental para uma recuperação posterior. Essas representações são oriundas da chamada Catalogação3, Catalogação Descritiva ou Representação Descritiva, nas quais originaram marcos teórico, códigos e regras como elementos necessários para a realização do Tratamento Descritivo da Informação (TDI). 


\subsection{Bases teóricas da catalogação descritiva}

Ao definir o que vem a ser a Catalogação Descritiva torna-se interessante apresentar a forma de como essa disciplina passou a fazer parte da atividade bibliotecária, inserida desde os primeiros cursos de Biblioteconomia desenvolvidos no Brasil, em São Paulo (1929) sob a responsabilidade de Rubens Borba de Moraes e Adelpha Figueiredo; houve críticas na presença dessa disciplina, alguns bibliotecários e instituições não aceitavam a sua importância no curso. De acordo com Castro (2002, p.28), "Enquanto o curso da Biblioteca Nacional (BN) ${ }^{4}$ voltava-se para formar um erudito-guardião, em São Paulo formava-se o técnico”. Após muitas discussões, a catalogação foi consolidada, e passou a fazer parte do currículo básico do curso de Biblioteconomia.

Percebe-se que a catalogação era considerada como uma atividade técnica. Mey e Silveira (2009) salientam que a atividade de catalogação não se limita apenas ao conhecimento da técnica, esta não deve deixar de almejar o lado intelectual do profissional, onde o recurso tecnológico irá apenas conceder a base para um trabalho humano; isto porque a catalogação envolve a sintaxe (posição e pontuação determinadas pelas regras) e a semântica (significado dos termos) facilitando a mensagem para o usuário. A catalogação ou representação bibliográfica é definida como:

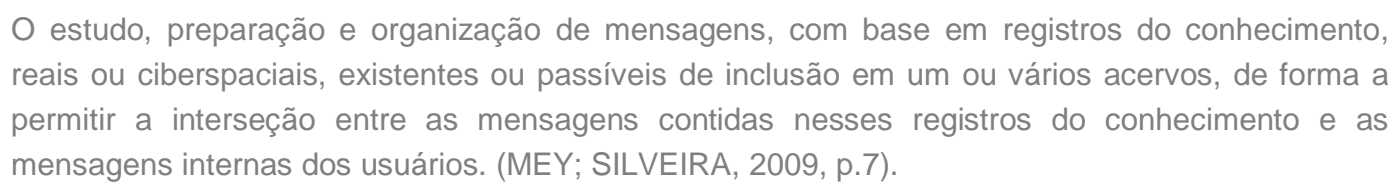

Podemos dizer que a Catalogação Descritiva caracteriza-se pela descrição do item bibliográfico, esteja ele armazenado em qualquer tipo de suporte, de modo a inserir todas as suas características que o identifique e o qualifique como recurso bibliográfico, tornando-o único e individual, garantindo sua unicidade e facilitando a recuperação pelo usuário.

\subsection{Catalogação descritiva: sua gênese e contemporaneidade}

Os períodos remotos destacam a presença das bibliotecas, datadas ao terceiro milênio a.C. e que sempre esteve presente a preocupação em organizar a informação, através das tecnologias vigentes a cada época (tábulas de argila, papiros, pergaminho, papel etc.). Bibliógrafos e livreiros interessados apenas na compilação dos seus catálogos e bibliografias desenvolviam as formas descritivas para suprir as necessidades informacionais (MEY; SILVEIRA, 2009).

As bibliotecas medievais criaram o inventário (listas de obras no acervo), que foi o ponto de partida para a construção dos catálogos estes se destacaram a partir das feiras comerciais realizadas no século XV, surgindo assim o primeiro catálogo de livreiros em 1564, nessa época não havia o intuito da criação de um código. Somente no século XIX as regras de catalogação foram sendo definidas. Charles Ami Cutter enfatizou os objetivos e funções do catálogo;

Em 1939 Antony Panizzi apresentou o primeiro código de catalogação propriamente dito conhecido como as 91 regras de Panizzi; Charles $\mathrm{C}$. Jewett foi o precursor do catálogo coletivo, e também criador de um código aprimorando as regras de Panizzi. Charles Ami Cutter, também ficou conhecido pela criação da tabela de notação de autor, influenciou e contribuiu para o primeiro código da American Library Association (ALA).

O estabelecimento das regras e a padronização da catalogação não foram construídos de forma simples, para se chegar à catalogação universal, bibliotecários e instituições renomadas foram aprimorando suas regras, tendo sempre o intuito da recuperação da informação pelo usuário, houve a criação de códigos como: Instruções Prussianas, ALA, em duas edições, Vaticana, AACR. À medida que os tipos de recursos se modificavam, aliado a um rápido crescimento de informações que deveriam ser organizadas, houve por iniciativa internacional os bibliotecários dos Estados Unidos a tentativa de criar formas para realizar a representação descritiva inserindo o recurso computacional. 
A necessidade de prover serviços em maior profundidade e em forma mais rápida a um maior número de usuários, bem como o aumento quantitativo dos materiais tradicionais, acrescentando ao aparecimento de novas formas de materiais, levaram as bibliotecas dos países desenvolvidos a optar pelo uso de computadores para processamento de suas operações internas. (BARBOSA, 1978, p.196).

Representada pela LC, em 1960 foi dado início a um projeto piloto que visava a conversão de dados catalográficos em forma legível por computador, denominado MARC.

Nesse contexto Mey e Silveira (2009) destacam a Conferência de Paris, iniciado em 1961, evento que veio para estabelecer e uniformizar as regras utilizadas na catalogação, nessa época ficou estabelecido à presença de cabeçalhos para nomes pessoais e títulos uniformes. De acordo com Santos e Corrêa (2009, p.23) "A Conferência de Paris, é, portanto, a primeira etapa importante de padronização em uma plataforma internacional”.

Correia (2008) salienta que a proposta por uma padronização foi idealizada pela International Federation of Library Associations and Institutions (IFLA) através de um evento conhecido como Reunião Internacional de Especialistas em Catalogação (RIEC) realizado em Copenhague, no qual foi apresentado um relatório ao qual era exposta a necessidade de uma padronização, estabelecendo-se as International Standard Bibliographic Description (ISBD), ou Descrição Internacional Normalizada, que são as regras para descrição por tipo de material e estabelece a pontuação utilizada na catalogação.

Em 1977, houve uma proposta em união da Organização das Nações Unidas para a Educação, Ciência e Cultura (UNESCO) e da IFLA, para criar diretrizes na construção de um programa de Controle Bibliográfico Universal ${ }^{5}$ (CBU) com o objetivo da reunião de todos os registros da produção bibliográfica de todos os países, para acesso universal. (CAMPELLO, 2006). Em 1978 foi publicado o Anglo-American Cataloging Rules second edition (AACR2), regido pelo estabelecido nos Princípios de Paris, e a descrição incorpora o padrão da ISBD, com atualizações constantes.

Partindo do princípio da catalogação, e diante do crescimento das publicações e o aparecimento de novos formatos, se faz presente na construção da representação bibliográfica um novo modelo das regras para melhor atender as necessidades de informação dos usuários. Nesse contexto são apresentados como um novo modelo conceitual para modelagem de catálogos os FRBR, ou Requisitos Funcionais para Registros Bibliográficos.

A eficiência na recuperação da informação e as necessidades de padronização cada vez mais presente na catalogação evidenciam um constante aprimoramento das regras, e no desempenho das atividades, principalmente em ambiente digital. Nesse cenário surge à proposta de substituição do código atual AACR2, apresentada pelo Joint Steering Commitee for Development of Revision of AACR chamada de Resource Description and Access (RDA).

Desta forma é pertinente destacar que a padronização da Catalogação Descritiva não inviabiliza a continuidade de estudos e atualizações nos códigos, modelos e formatos utilizados, proporcionando melhor adequação no desenvolvimento dessa atividade para uma recuperação mais significativa e intuitiva pelo usuário. Partindo desse contexto, nota-se a influência que exerce as tecnologias computacionais e o desenvolvimento das Tecnologias da Informação e Comunicação (TIC) na práxis da Catalogação Descritiva. Ao acompanhar essa evolução, verifica-se que essa atividade clássica, passa a fazer parte de outros ambientes informacionais, e a ela é atribuído o termo metadados. Para essa pesquisa considera-se metadados como:

[...] atributos que representam uma entidade (objeto do mundo real) em um sistema de informação.

Em outras palavras, são elementos descritivos ou atributos referenciais codificados que representam características próprias ou atribuídas às entidades; são ainda dados que descrevem outros dados em um sistema de informação, com o intuito de identificar de forma única uma entidade (recurso informacional) para posterior recuperação (ALVES, 2010, p.47).

No contexto da biblioteca pode-se dizer que os catálogos representam um exemplo típico de metadados, pois neles são armazenados os dados descritivos dos recursos auxiliando os usuários na recuperação. A partir dos metadados são construídos os padrões ou formatos de metadados, que determinam a interoperabilidade em ambientes informacionais digitais. 
Os padrões de metadados são estruturas de descrição constituídas por um conjunto prédeterminado de metadados (atributos codificados ou identificadores de uma entidade) metodologicamente construídos e padronizados. O objetivo do padrão de metadados é descrever uma entidade gerando uma representação unívoca e padronizada que possa ser utilizada para recuperação da mesma. (ALVES, 2010, p.47-48).

O formato MARC passou a ser um padrão a nível internacional e bastante difundido em outros países, proporcionando uma catalogação diversificada e dificultando o intercâmbio de informações, o que levou a LC, a considerar a criação de um único formato. Após estudos e discussões houve a união do USMARC (desenvolvido pela Inglaterra), e o CAN/MARC (desenvolvido pelo Canadá), e em 1998 a harmonização desses formatos deu nome ao MARC 21 (STWART 1999 apud SANTOS; FLAMINO, 2004).

O MARC 21 é um formato desenvolvido pelos bibliotecários para comportar as informações numa estrutura de computador, esse mecanismo possibilita a codificação da informação pela máquina que nos dará a representação da informação, sua estrutura contempla as regras descritivas do AACR2 de modo padronizado e apresenta-se como o primeiro formato para a comunicação de registros bibliográficos. (CASTRO, 2008).

Como se pode perceber, de acordo com os fundamentos teóricos encontrados na literatura científica, que o formato MARC21 apresenta uma estrutura muito importante para as bibliotecas visto o seu potencial de detalhes específicos para esta área. Castro (2008) ressalta que o desenvolvimento tecnológico leva um revisar nos padrões dos metadados e, para atender a comunidade e acompanhar os avanços tecnológicos, a LC integrou a linguagem computacional XML ao padrão MARC21, resultando no padrão MARCXML.

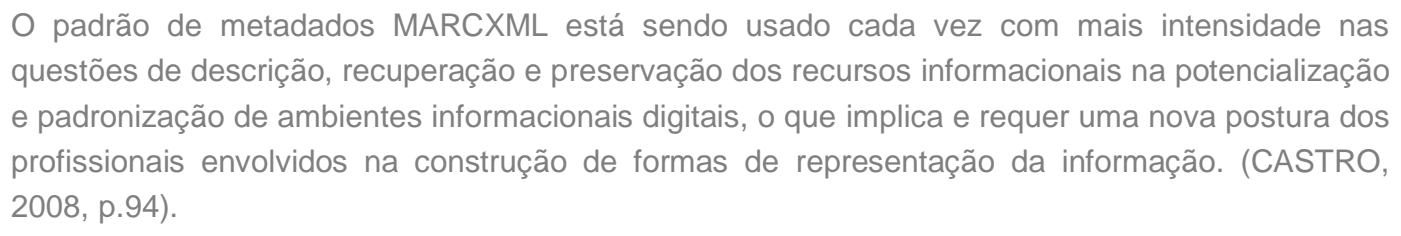

Como pode ser visto a Catalogação Descritiva sustenta-se numa base de regras e esquemas internacionais que são revisados de forma constante, estabelecendo a prática da catalogação como um mecanismo contemplado por padrões compatíveis com a realidade vigente.

É interessante compreender que a sistematização do processo evolutivo da Catalogação Descritiva, bem como os mecanismos e instrumentos apresentados são utilizados na padronização do Tratamento Descritivo da Informação (TDI).

A catalogação, como mecanismo essencial para a padronização e descrição das informações, é construída a partir de regras que ofereçam o máximo de padronização e minimizem as interpretações individuais, procurando garantir a unicidade do item informacional representado e, ao mesmo tempo, sua universalidade. (SANTOS; CORRÊA, 2009, p.20).

A forma padronizada estabelecida na Catalogação Descritiva decorre da contribuição de indivíduos e organizações ao longo dos séculos, esta determinava um controle bibliográfico de modo a inserir nessa atividade princípios, fundamentos e métodos na realização do Tratamento Descritivo da Informação e dos instrumentos utilizados na representação (ALVES, 2010), a fim de potencializar a busca e a recuperação pelo usuário final.

\section{A educação continuada do bibliotecário na perspectiva da biblioteca universitária}

Diante da presença das Tecnologias da Informação e Comunicação (TIC) que atuam diretamente nos serviços oferecidos, sobretudo, nas Bibliotecas Universitárias, verifica-se que a Educação Continuada pode constituir como fator elementar para o bibliotecário/catalogador, no tocante às constantes atualizações que permeiam à atividade de catalogação. 


\subsection{A biblioteca universitária: dimensão contextual}

A evolução tecnológica das bibliotecas passou e continua passando por transformações decorrentes da presença de novas tecnologias, as quais dão agilidade nos processos informacionais. Cunha (2000) destaca as eras representativas das bibliotecas no decorrer do tempo, tais como, Era I: diz respeito à biblioteca tradicional moderna; Era II: a biblioteca automatizada; Era III: bibliotecas eletrônicas; Era IV: referem-se às bibliotecas digitais e virtuais. De acordo com Miranda (2003, p.51).

Toda a evolução das bibliotecas - sejam elas públicas, universitárias, especializadas ou legislativas - esteve relacionada com a evolução das tecnologias de registro do conhecimento, passando por inscrições rupestres, papiros, códices de pergaminho, livros impressos até as versões atuais em CD-ROM ou e-books, tanto em coleções estáticas nas estantes até as versões ditas virtuais que animam a web.

Verifica-se a maturidade das bibliotecas, e consequentemente dos serviços que elas oferecem, e nesse contexto compreende-se que, as tecnologias presentes nas bibliotecas representam celeridade nas informações, que altamente produzidas exigem o armazenamento adequado, potencializando a busca pela informação.

A evolução das bibliotecas tem merecido grande destaque ao longo destes anos, no que se refere ao desenvolvimento e uso de tecnologias, principalmente as da informação e comunicação (TIC) que se potencializam por meio dos novos recursos de acesso e formatos de intercâmbio advindos principalmente da área de Biblioteconomia no tratamento de informações bibliográficas e catalográficas. (CASTRO, 2008, p.49).

Morigi e Pavan (2004) ressaltam que as bibliotecas no mundo contemporâneo, evidenciam a presença de técnicas e processos automatizados, e embasados no conhecimento científico vieram a realizar o tratamento diferenciado em relação ao armazenamento, disseminação e recuperação da informação. "Ao empregar as tecnologias de informação e comunicação, as bibliotecas universitárias criaram novos serviços e aperfeiçoamentos aos já oferecidos". (MORIGI; PAVAN, 2004, p.122).

Pode-se considerar que, na utilização das tecnologias, as bibliotecas reformulam os seus serviços especializados, a exemplo, os instrumentos de Tratamento Descritivo da Informação, para aprimorar a recuperação da informação para os usuários.

É interessante destacar através do importante papel que exerce a biblioteca na sociedade, os profissionais que nela trabalham, no caso, os bibliotecários precisam se apropriar do seu novo aspecto, que aproxima verdadeiros montantes de informação, esta não somente adaptada para a cultura e a preservação, mas retrata o quanto a informação armazenada precisa ser tratada, armazenada, descrita e representada para melhor atender aos que dela solicitam.

Uma equipe bibliotecária bem preparada é capaz de atender de maneira satisfatória, pois a biblioteca universitária brasileira não atende somente à comunidade local como ocorria até a década de 80. Em pleno século XXI, as bibliotecas oferecem serviços on-line, onde o usuário interessado em seu acervo está presente também virtualmente e isso requer dos bibliotecários outros conhecimentos até então inexistentes à época como, por exemplo, usar a Internet como real ferramenta de trabalho do dia-a-dia. (ALMEIDA, 2007, p.14).

Considerando as mudanças no ambiente informacional é de fundamental importância que os profissionais fiquem atentos a esse novo ambiente de trabalho, bem como às necessidades exigidas pela sociedade, na qual preconizam o aprimoramento e atualizações nas suas funções.

\subsection{A educação continuada do bibliotecário}

A Educação Continuada vem sendo palco de discussões e reflexões em diversas áreas do conhecimento, em decorrência da evolução do processo educacional em que passa a sociedade. Atento a essa questão Corrêa (2001) 
alerta que a formação de um profissional é adquirida junto às instituições de ensino como determinante para a competência especializada de uma profissão, possibilitando ao profissional aptidão a lidar com os determinantes surgidos ao longo de uma carreira. Através das constantes transformações da sociedade, nas esferas políticas, sociais, econômicas e tecnológicas, a formação então passa a necessitar de um complemento. Nesse contexto destaca-se a Educação Continuada, a fazer parte da complementação dos estudos do bibliotecário.

A Educação Continuada está inserida nas profissões de forma a implementar os conhecimentos atualizados na carreira dos profissionais, na Biblioteconomia não é diferente. Castro (2002) salienta que na reestruturação do curso de Biblioteconomia da Biblioteca Nacional em 1944, já havia uma preocupação em estabelecer a Educação Continuada: Curso fundamental de Biblioteconomia; Curso Superior de Biblioteconomia (CSB); Cursos Avulsos (CA).

Os Cursos Avulsos tinham a "finalidade de atualizar os conhecimentos dos bibliotecários e bibliotecário-auxiliares, divulgar conhecimentos sobre biblioteconomia e promover a homogeneidade básica dos serviços de bibliotecas" (NEVES apud CASTRO, 2002, p.30). O que o autor considera ser o início da sistematização da Educação Continuada formal do bibliotecário.

A necessidade de Educação Continuada foi aos poucos adquirindo nova realidade, sendo visualizada como um caminho para acompanhar as necessidades do mercado.

Em seus estudos Tarapanoff (1997) traça o perfil do profissional da informação no Brasil, destacando fundamental a importância do treinamento e da Educação Continuada na carreira do profissional que deseja se consolidar num cenário de permanente mudança. Moreno et al. (2007) e Corrêa (2001), consideram que através da Educação Continuada, o profissional concretiza sua formação, visto que o conhecimento não se limita ao da graduação.

Somente a educação continuada fará com que o bibliotecário possa adquirir o aperfeiçoamento necessário para o seu crescimento, renovando os conhecimentos e especializando-se na área de seu maior interesse e/ou atuação (MORENO et al., 2007, p. 2).

Percebe-se que, compreender a importância da Educação Continuada é fundamental para que essa prática tornese integrada na vida do profissional, no momento em que esta passa a ser exercida, irá complementar a carreira do indivíduo, tão exigida na sociedade atual. Essa prática busca contribuir com possíveis distorções geradas pela formação inicial, como também aproximar-se do aprendizado inovador, alterado pelas transformações sociais, refazendo a forma de pensar, sentir e agir das novas gerações.

Ruchinski (2009, p. 28) define Educação Continuada como: "O processo contínuo de atualização, aperfeiçoamento, treinamento e aprimoramento das qualificações e habilitações individuais de cada profissional".

"A educação continuada pode ser definida como atividades educacionais que têm por objetivo atualizar e desenvolver $\mathrm{o}$ conhecimento $\mathrm{e}$ as habilidades profissionais, de forma a permitir ao profissional um melhor desempenho de sua função" (CRESPO et al., 2006, p. 3).

Nesta pesquisa entende-se como Educação Continuada todo aprendizado adquirido nas diversas formas, realizado após a educação formal possibilitando o conhecimento atualizado do profissional. (SANTOS, 2013).

Em relação aos formatos da Educação Continuada identificamos na literatura científica várias tipologias que podem ser desenvolvidos por iniciativas pessoais e/ou institucionais, e que evoluíram ao longo dos anos. Cunha (1984) descreve como formas de Educação Continuada, a Leitura de livros e periódicos profissionais; Cursos oferecidos em reuniões profissionais; Estudos domiciliares ou individuais; Pesquisa em Biblioteconomia; Visitas e estágios.

Autores como Naves (1999), Zanaga (1989) e Pavão et al. (1998), citados na obra de Ruchinski (2009) evidenciam ainda como tipologias de Educação Continuada a Educação à distância; o Treinamento em local de trabalho; Reuniões Associativas e Grupos de trabalho.

Numa abordagem mais recente foram identificadas as concepções tipológicas de EC elaboradas por Giannasi (1999) ressaltando que a Educação Continuada é um termo amplo que envolve atividades variadas de aprendizagem, poderá ser proporcionada por cursos formais de pós-graduação, lato sensu ${ }^{6}$ e stricto sensu ${ }^{7}$, ou mesmo leitura de livros, palestras, seminários, cursos, treinamentos e eventos em geral. 
Moreno et al. (2007) concordam com Corrêa (2001) ao discorrer sobre as várias formas de EC tais como, os cursos de especialização, participação em eventos (palestras, seminários, simpósios, congressos etc.) e os cursos de curta duração realizados após a educação formal. Na concepção de Crespo et al.(2006) são formatos da Educação Continuada a leitura em geral, eventos (palestras e reuniões), cursos e treinamentos.

Para o desenvolvimento dessa pesquisa serão abordadas as tipologias de EC, nas modalidades de cursos e eventos relacionados à prática da catalogação (presencial ou à distância) após a educação formal, o que de acordo com a pesquisa apresentada por Santos (2013) formam as modalidades mais exercidas pelos profissionais.

\subsection{A Educação continuada e o papel do catalogador}

O curso de Biblioteconomia volta suas atenções para a formação profissional de maneira abrangente, no qual consideram mudanças empíricas vivenciadas na sociedade. Em relação à Educação Continuada dos bibliotecários, algumas funções são merecedoras de maior atenção, como a Catalogação Descritiva. Não queremos dizer aqui que as outras funções sejam menos importantes, mas a Catalogação Descritiva proporciona o elo de acesso e da recuperação da informação para o usuário, sem falar das adaptações e atualizações dos padrões que ocorrem de maneira constante para permitir o melhoramento dessa atividade. Dessa forma considera-se que:

\section{A catalogação, como tal, continua sofrendo mudanças em sua natureza e processos, o que determina a necessidade de conhecimento em relação a essas mudanças, e treinamento em relação às práticas delas resultantes; [...] Em função de todas as mudanças apontadas, torna-se necessário alcançar, em nível de currículo, um equilíbrio bem dosado entre fundamentação e prática (BAPTISTA, 2006, p. 9)}

Tal afirmação reforça a ideia de que a Catalogação Descritiva é uma atividade que busca sempre acompanhar as tendências das tecnologias vigentes, e cabe ao bibliotecário manter-se consciente dessa necessidade de atualização. A atividade da Catalogação Descritiva é parte do conhecimento específico da profissão de bibliotecário, e que dentre outras atividades sofrem o processo evolutivo gerado pela presença das tecnologias vigente. Nesse sentido, conforme afirmam Pereira e Rodrigues (2002, p.232):

\section{[...] somente um processo contínuo de aprendizagem poderá dar condições para o catalogador atualizar-se continuamente e estar apto a desenvolver e discutir tais procedimentos, visto que a ele cabe a função de trabalhar com recursos tecnológicos e oferecer facilidades no processo de intercâmbio da grande massa informacional que dispõe-se.}

Pode-se perceber que o processo evolutivo da Catalogação Descritiva é um caminho natural para essa atividade que se utiliza da produção documental como matéria-prima, e esta por sua vez, passa por diferentes formatos e estruturas, que abarcam os recursos tecnológicos vigentes a cada época. Nesse contexto, verifica-se que a Educação Continuada tem permitido o aperfeiçoamento de atividades que exigem conhecimento atualizado do bibliotecário, por exemplo, na atividade da catalogação.

\section{A promoção da educação continuada dos bibliotecários}

Procura-se, nesse momento, discorrer sobre a promoção da Educação Continuada, destacando os órgãos de classe como organismos de apoio ao profissional que busca atualizar-se no mercado de trabalho.

\subsection{Possibilidades e limitações da educação continuada}

A tendência de especialização ganhou destaque, sobretudo, da maior necessidade de informação da sociedade atual, da modernização das funções bibliotecárias, que se utiliza de tecnologias informacionais recentes, e tornam os usuários cada vez mais rigorosos na qualidade da informação. Para atender tais exigências o profissional deve desenvolver o seu conhecimento de maneira constante.

Uma nova atitude deve ser adotada pelos bibliotecários no sentido de oferecer aos clientes serviços com qualidade, rapidez, precisão e atualidade, sendo para isso necessário investir em treinamento de recursos humanos e, assim estabelecer uma nova cultura no ambiente de trabalho. (RAMOS, 1999, p. 11). 
A Educação Continuada, no entanto, deve ser planejada de modo a não limitar o profissional apenas ao acesso a informações atualizadas, é preciso transformar o ambiente de trabalho, destacando o seu papel profissional, que deve ser executado de forma eficiente e competitiva, possibilitando uma reflexão crítica de sua prática profissional. (GIANNASI, 1999).

Proceder à Educação Continuada torna-se uma tarefa sábia para o profissional que vivencia novos cenários, porém, como realizar esse aprendizado? A nossa sociedade tem preparado os profissionais bibliotecários nesse contexto?

Sob a ótica de algumas pesquisas realizadas por Moreno et al.(2007) e Corrêa(2001) verifica-se como vem sendo disponibilizada a Educação Continuada para os bibliotecários; destacam-se os órgãos de classe de fundamental importância nessa promoção pelo aprendizado contínuo, e que vem contribuindo de maneira satisfatória nessa conduta. Conforme fundamentado por Moreno et al. (2007) promover a Educação Continuada deve ser atribuição de todos os seguimentos responsáveis pelo desenvolvimento de determinada área profissional, em busca de contribuir para o acesso as variadas formas de Educação Continuada, minimizando assim as dificuldades encontradas pelos profissionais.

\subsection{A contribuição das Associações e do Conselho Regional de Biblioteconomia (CRB) na educação continuada do bibliotecário}

No desenvolvimento da Educação Continuada o profissional pode manifestar-se individual, ou mesmo a partir de promoções concedidas por meio das organizações de classe, este poderá servir de apoio aos profissionais na sua formação.

Pesquisa realizada por Moreno et al.(2007) destaca a importância do incentivo da Educação Continuada, proporcionada pelos órgãos de classe dos bibliotecários. Sobre o assunto os autores caracterizam entidades de classe vinculadas à Biblioteconomia, tais como, os Conselhos de Classe $^{8}$, as Associações ${ }^{9}$ e os Sindicatos ${ }^{10}$. Nesse sentido, pode-se entender que as entidades de classe propiciam ao bibliotecário a oportunidade de acesso às variadas formas de Educação Continuada, motivo este que poderá despertar o interesse do profissional em sua capacidade de atualização.

Algumas organizações de âmbito nacional destacam-se no intuito de favorecer a Educação Continuada, através de eventos e discussões na área de estudo, cita-se a Associação Brasileira de Educação em Ciência da Informação (ABECIN), a Federação Brasileira de Associação de Bibliotecários, Cientistas da Informação e Instituições (FEBAB) e a Associação Nacional de Pesquisa em Ciência da Informação (ANCIB). (ROZADOS, 2007).

Para o âmbito desta pesquisa é pertinente destacar como órgãos de apoio aos bibliotecários de Sergipe na sua Educação Continuada o CRB5, Conselho responsável pelas profissionais bibliotecários das regiões da Bahia e de Sergipe, e a Associação Profissional de Bibliotecários e Documentalistas de Sergipe (APBDSE).

\subsection{Temas de cursos expoentes na área da catalogação descritiva}

Para enfrentar o desafio de acompanhar as revisões, atualizações e os novos tipos de estruturas representadas pela atividade de catalogação são oferecidos cursos aos profissionais que necessitam acompanhar essas mudanças; identificamos em sites na Internet da Federação Brasileira de Associações de Bibliotecários (FEBAB), e (Informar - RS), alguns temas mais desenvolvidos sobre Catalogação Descritiva no ano de 2012.

- Atualização em AACR2;

- Catalogação em base de dados no formato MARC21;

- Catalogação em base de dados de acordo com a última revisão do AACR2 e de introdução ao RDA (sua aplicação): 
Esses cursos são oferecidos em caráter presencial, ou à distância e leva ao profissional à interação nos conteúdos relacionados à Catalogação Descritiva, o que nos parece uma boa alternativa para os profissionais não se "perderem" em meio às atualizações. Porém, para participar desses cursos, os bibliotecários terão que dispor de recursos financeiros próprios, e apesar dos descontos propostos, ainda pode significar um empecilho para muitos profissionais.

\section{Proposta de educação continuada em catalogação descritiva no estado de Sergipe: recomendações funcionais}

$\mathrm{Na}$ captação dos dados foram aplicados questionários aos bibliotecários do estado de Sergipe. Para dar sustentação à pesquisa foram colhidos dados documentais de promoção à Educação Continuada dos últimos dez anos desenvolvidos em Sergipe pelos órgãos de classes da Biblioteconomia, tais como APBDSE e CRB5.

A população analisada foi constituída por bibliotecários das principais universidades do estado de Sergipe, no âmbito público e privado - Universidade Federal de Sergipe (UFS) e Universidade Tiradentes (UNIT), por possuírem o maior número de profissionais em atividade cadastrados no CRB5, sendo elencados os seguintes pontos:

- Perfil do Bibliotecário: Dados que compreendem informações pessoais do profissional como, idade, instituição de formação e outros.

- Atividades na Biblioteca: Informações sobre atividades relacionadas à Catalogação Descritiva desenvolvida na biblioteca, verificando os instrumentos utilizados pelos profissionais.

- $\quad$ Atividades de Educação Continuada: Abordam questões voltadas para a participação do bibliotecário na Educação Continuada.

Durante a elaboração dessa investigação foi realizado contato com o presidente do CRB5 e a Diretora da APBDSE solicitando as atividades desenvolvidas de Educação Continuada em Catalogação Descritiva nos últimos dez anos. Sendo o pedido aceito, essas informações foram fundamentais para a análise dos dados da pesquisa.

A apresentação dos resultados para melhor divulgação das informações foi realizada e sistematizada em gráficos que retratam de forma efetiva a Educação Continuada em Catalogação Descritiva nas Bibliotecas Universitárias de Sergipe.

\subsection{Parte A - Perfil dos bibliotecários}

Buscou-se verificar o nível de qualificação dos bibliotecários na sua pós- graduação lato e stricto sensu (especialização, mestrado e doutorado). Constatou-se que 50\% dos bibliotecários possuem apenas a graduação; com 46\% apresentaram-se aqueles com pós-graduação lato sensu; e com $4 \%$ os profissionais que possuem mestrado; no nível de doutorado não foram identificados nenhum participante dessa pesquisa. 
GRÁFICO 01: Grau de formação dos sujeitos.

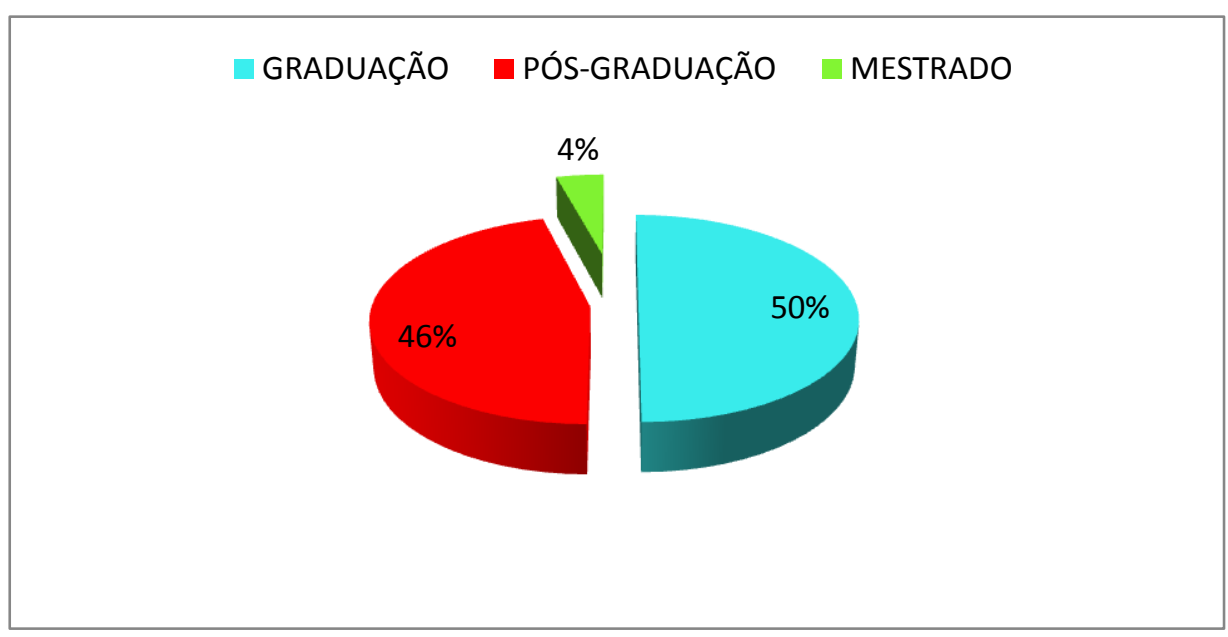

Fonte: Santos (2013).

GRÁFICO 02: Vínculo associativo dos bibliotecários na APBDSE.

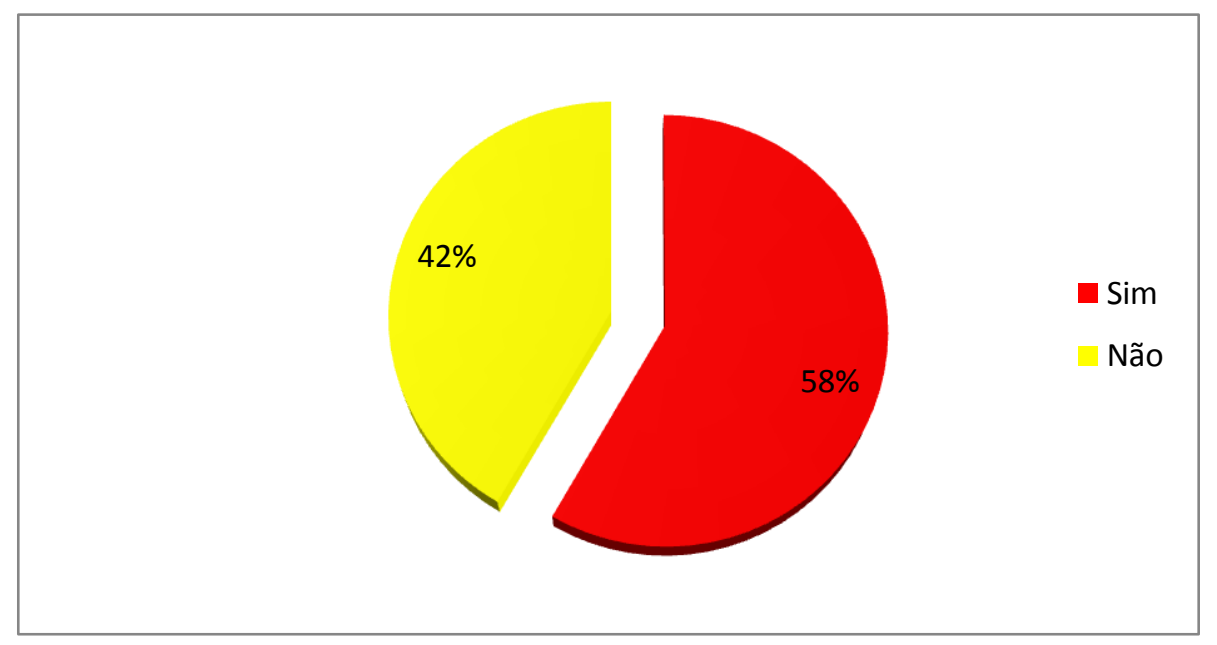

Fonte: Autores (2013).

Procurou-se saber se os bibliotecários participam do movimento associação do estado; foi observado que $58 \%$ possuem vínculo com a associação de classe e $42 \%$ não possuem tal vínculo. 


\subsection{Parte B - Atividades na biblioteca}

Nessa seção buscou-se analisar a atuação do bibliotecário em setores específicos da biblioteca.

GRÁFICO 03: Setor de trabalho exercido pelo bibliotecário.

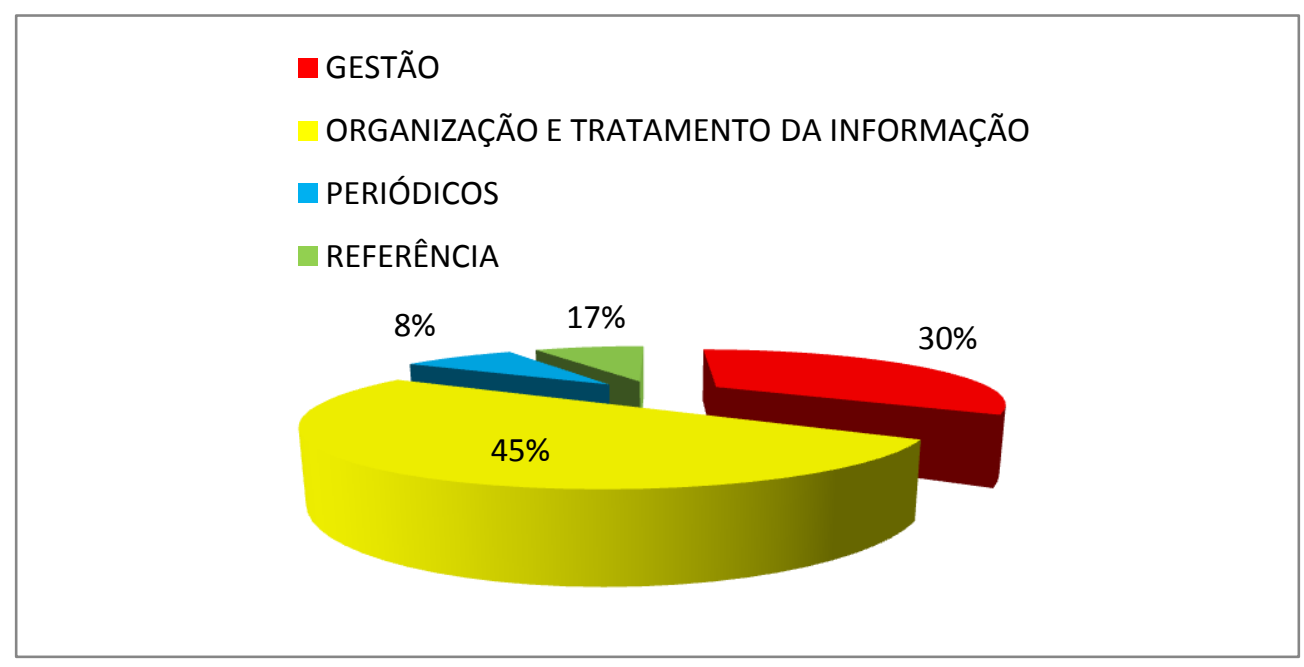

Fonte: Autores (2013).

Os resultados demonstram que na sua maioria, os bibliotecários desenvolvem suas atividades no setor de Organização e Tratamento da Informação ${ }^{11}$, totalizando $45 \%$, o setor de gestão ${ }^{12}$ abarca $30 \%$ dos profissionais, $17 \%$ executam atividades no setor de referência ${ }^{13}$, e apenas $8 \%$ nos periódicos.

GRÁFICO 04: Instrumentos utilizados na Catalogação Descritiva.

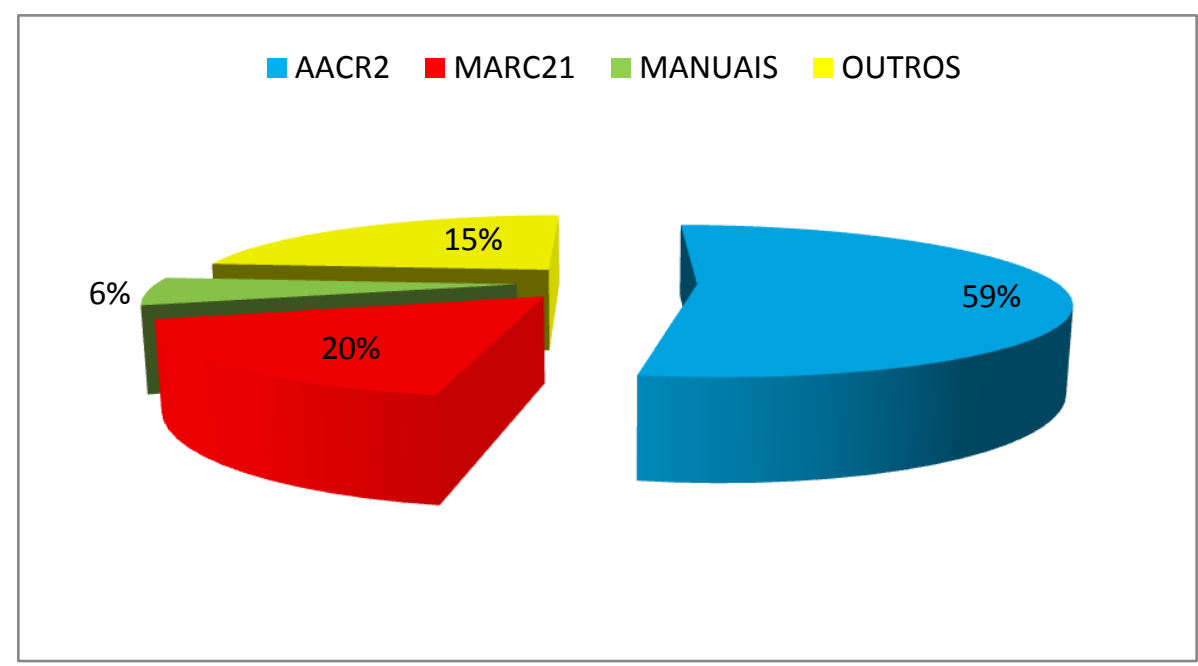

Fonte: Autores (2013). 
Os bibliotecários relataram na sua maioria que utilizam o AACR2 no desenvolvimento da atividade de catalogação descritiva totalizando 59\%; o uso do MARC 21 aparece com 20\%; 6\% informaram fazer uso de manuais disponibilizado em sites (Pergamum) ${ }^{14}$ ou impressos (Não brigue com a catalogação) ${ }^{15}$, e $15 \%$ informaram fazer uso de outros tipos de instrumentos como consulta a sites institucionais como da Biblioteca Nacional(BN).

\section{GRÁFICO 05: Promoção da Educação Continuada em Catalogação Descritiva no ambiente de trabalho.}

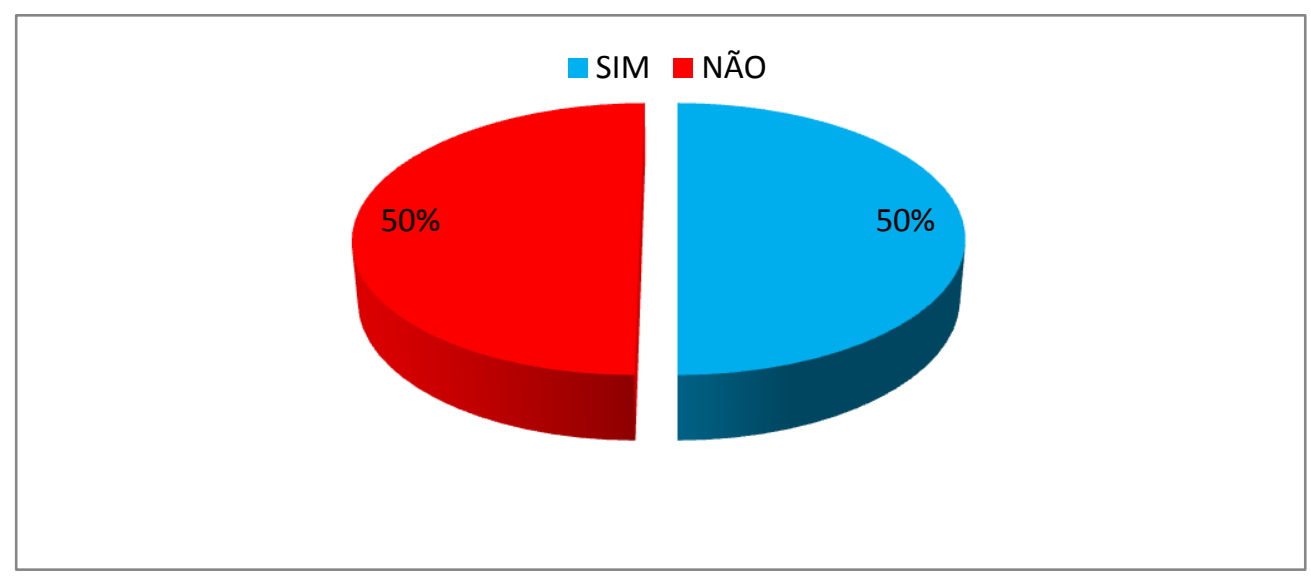

Fonte: Autores (2013).

No que se refere à promoção da Educação Continuada no local de trabalho, o resultado demonstra percentual igualitário, com $50 \%$ dos entrevistados declarando afirmativo, e 50\% declaram ser negativas as ações que viabilizem a atualização dos bibliotecários em seu local de trabalho.

\subsection{Parte C - Atividades de educação continuada}

GRÁFICO 06: Necessidade de Especialização em Catalogação Descritiva.

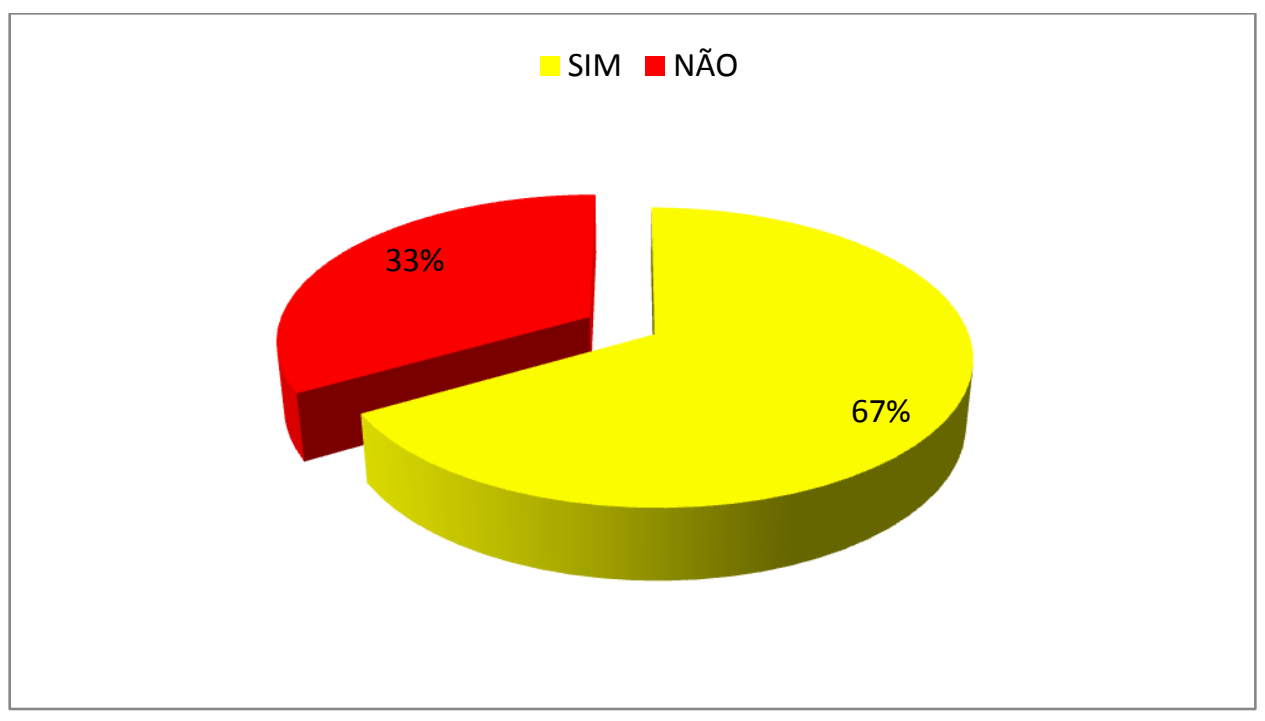

Fonte: Autores (2013). 
Buscando conhecer se os bibliotecários avaliam e refletem sobre a importância da Catalogação Descritiva como atividade de constante atualização, $67 \%$ dizem sentir a necessidade de realizar especialização nessa área; enquanto $33 \%$ declararam não sentir essa necessidade.

GRÁFICO 07: Opção de Educação Continuada em Catalogação Descritiva.

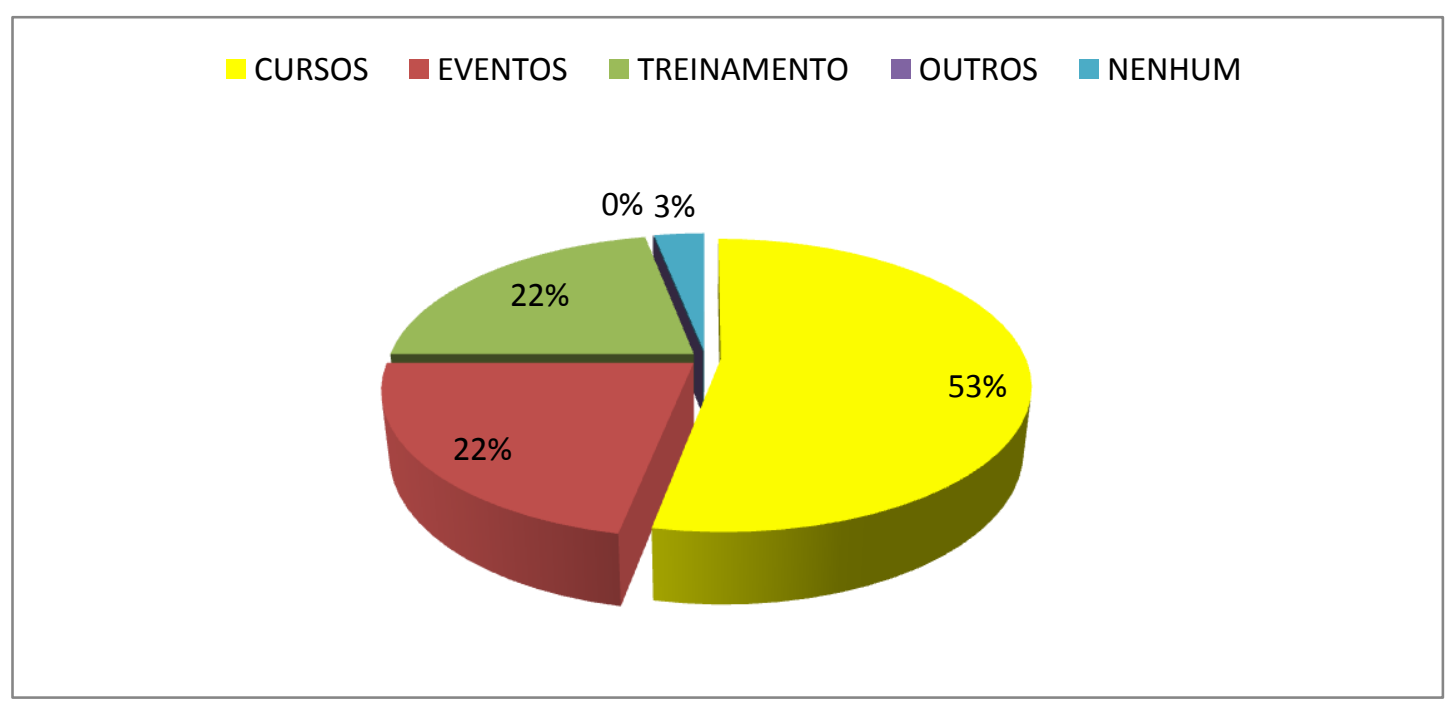

Fonte: Autores (2013).

Os resultados constataram que a Educação Continuada é desenvolvida com $53 \%$ através de cursos, $22 \%$ optam por meio de eventos; ainda com $22 \%$ foram identificados os treinamentos e $3 \%$ afirmaram não realizar nenhuma forma de Educação Continuada.

GRÁFICO 08: Educação Continuada à distância

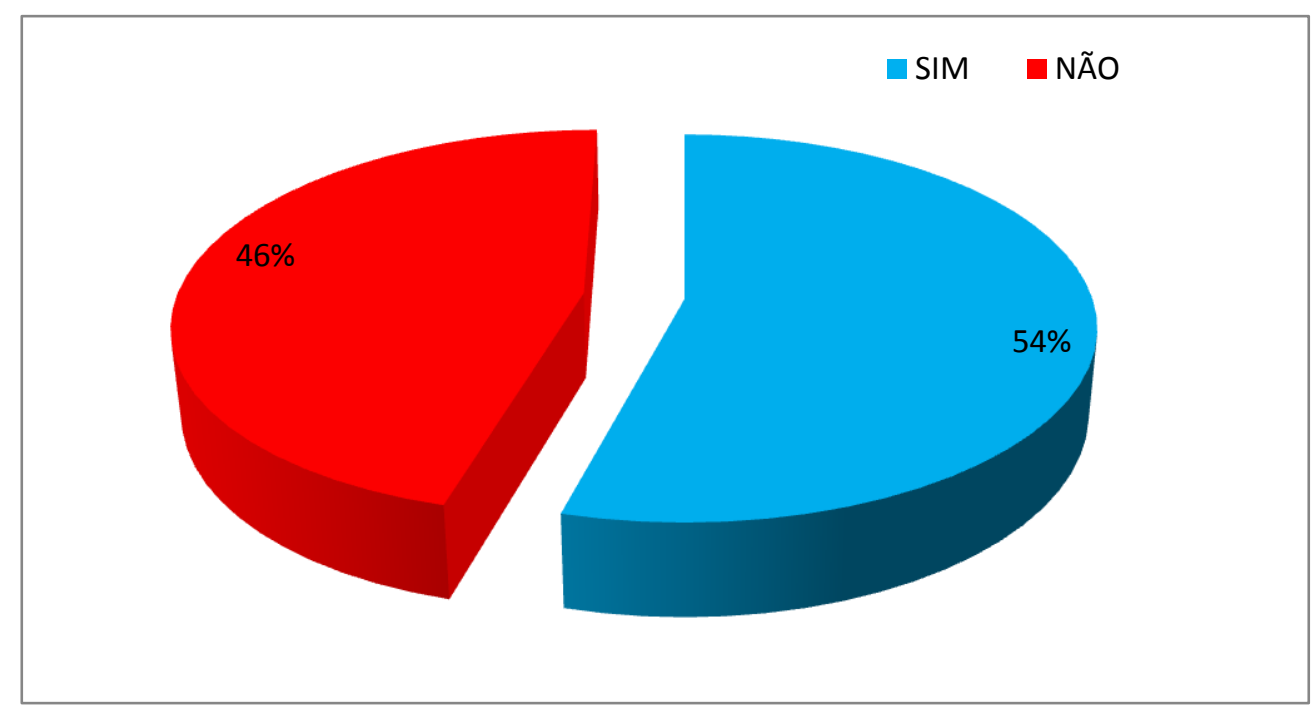

Fonte: Autores (2013). 
Os resultados constataram que a Educação Continuada desenvolvida na modalidade à distância faz parte de 54\% das respostas dos sujeitos da pesquisa, e 46\% não optam por esse tipo de aprendizagem.

\section{GRÁFICO 09: Dificuldades em praticar a Educação Continuada em Sergipe.}

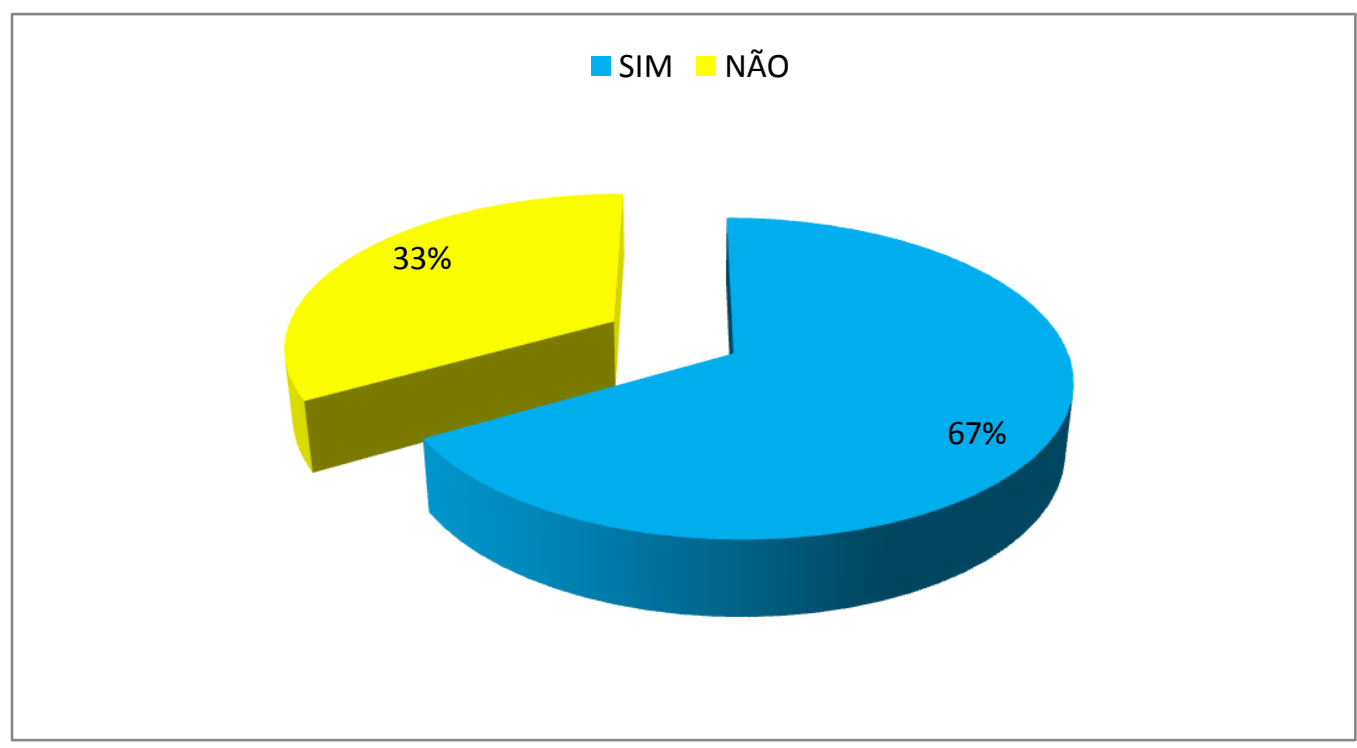

Fonte: Autores (2013).

Visualizados no Gráfico 09, nota-se que os bibliotecários de Sergipe reconhecem que a prática da Educação Continuada é amplamente dificultada totalizando $83 \%$ das respostas e apenas 17\% não vêem dificuldades nessa realização.

GRÁFICO 10: Tipos de dificuldades em praticar a Educação Continuada.

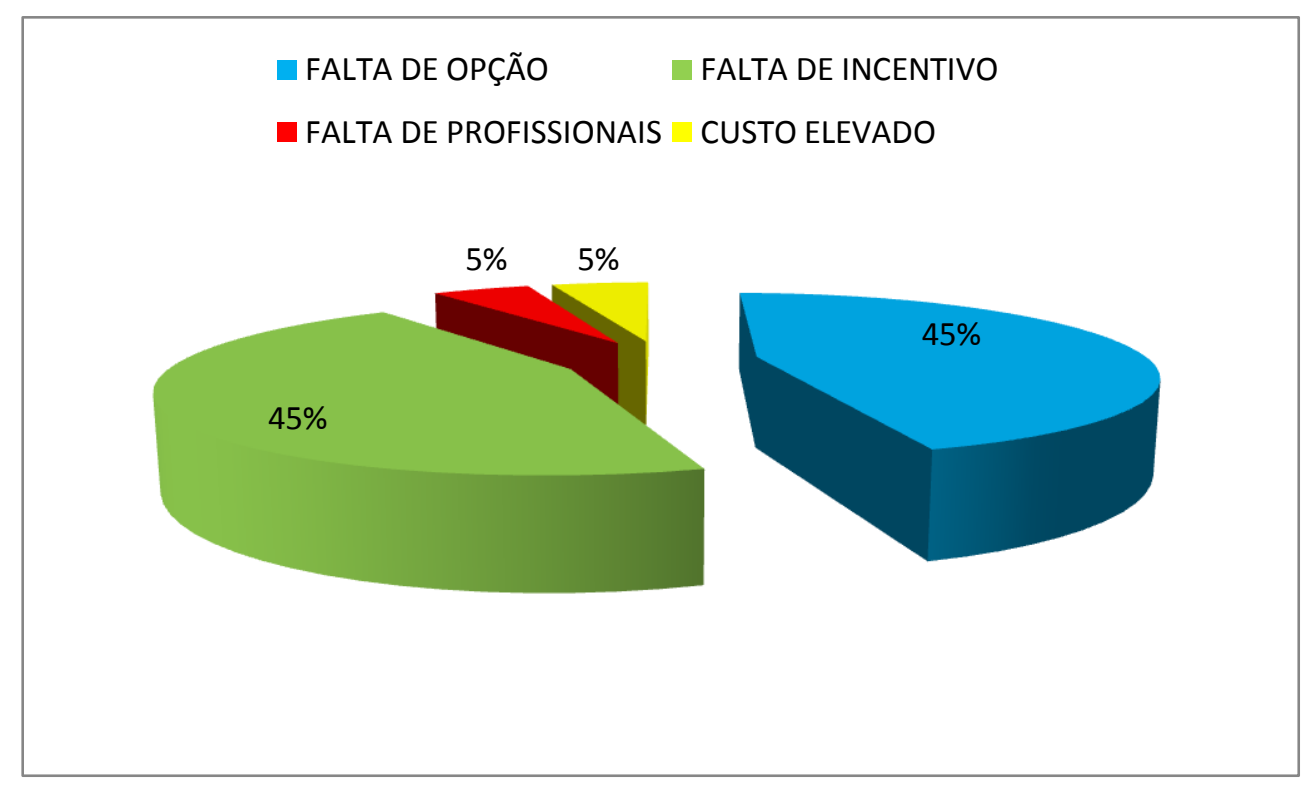

Fonte: Autores (2013). 
Em continuidade a questão anterior, buscou-se identificar as dificuldades em realizar a Educação Continuada, para tanto os entrevistados relataram as seguintes opiniões: $45 \%$ alegam Falta de opção; ainda com $45 \%$ dizem que há Falta de incentivo; $5 \%$ a Falta de profissionais, e 5\% alegam Custo elevado.

A segunda etapa da pesquisa foi à realização exaustiva dos principais cursos e eventos promovidos pelos órgãos de classe, desenvolvidos pela APBDSE e pelo CRB5, no estado de Sergipe, no período de 2002-2012. Destaca-se que através da promoção de eventos, palestras e cursos, a APBDSE contribuiu com a Educação Continuada dos bibliotecários conforme apresentado no Quadro 1 (um).

QUADRO 1: Atividades de Educação Continuada promovidos pela APBDSE.

\begin{tabular}{|c|c|c|}
\hline \multicolumn{3}{|c|}{ ATIVIDADES DE EDUCAÇÃO CONTINUADA PROMOVIDAS PELA APBDSE } \\
\hline FORMATO & NOME & PERÍODO \\
\hline Curso & $\begin{array}{l}\text { Organização de Documentos - Arquivo morto: Corte } \\
\text { Este Prejuízo da sua Empresa }\end{array}$ & 05 de junho de 2004 \\
\hline Curso & Como organizar e implantar centros de documentação & 09 e 10 de outubro de 2004 \\
\hline Curso & $\begin{array}{l}\text { Certificação do Sistema da Qualidade de Bibliotecas e } \\
\text { Organizações de Informação: Normalização por } \\
\text { requisitos ISO 9001:2000 }\end{array}$ & 10 e 11 de dezembro de 2005 \\
\hline Workshop de Bibliotecas & $\begin{array}{l}\text { Instituições Informacionais, suas características e } \\
\text { funções }\end{array}$ & 10 de junho de 2006 \\
\hline Workshop de Bibliotecas & Marketing da informação & 24 de novembro de 2007 \\
\hline Curso & Encadernação e restauração de livros & 16 a 18 de julho de 2008 \\
\hline Curso & Encadernação e restauração de livros & 20 de junho de 2009 \\
\hline Evento & I Encontro de Integração e Informação da APBDSE & 22 de agosto de 2009 \\
\hline Workshop & Organização e Orçamentos de Serviços de Informação & 13 de março de 2009 \\
\hline Curso & Encadernação e restauração de livros & 19 e 20 de janeiro de 2010 \\
\hline Seminário & Atualização profissional & 15 de maio de 2010 \\
\hline VI Workshop & Sistema CFB/CRB & 21 e 22 de maio de 2010 \\
\hline Curso & Auxiliar de biblioteca & $\begin{array}{c}14,21 \text { e } 28 \text { de novembro de } 2011 \text { / } 5 \text { a } \\
12 \text { de dezembro de } 2011\end{array}$ \\
\hline Curso & Introdução à informação audiovisual & 19 de Março de 2011 \\
\hline Curso & $\begin{array}{l}\text { Imagens fotográficas, informação, análise e } \\
\text { significação. }\end{array}$ & $\begin{array}{l}30 \text { de abril de } 2011 \\
17 \text { de novembro de } 2011\end{array}$ \\
\hline Curso & $\begin{array}{l}\text { Capacitação de Pessoal na área de Preservação e } \\
\text { Conservação de acervos documentais. }\end{array}$ & 15 de setembro de 2012 \\
\hline
\end{tabular}

Fonte: Autores (2013). 
Notou-se que os cursos e eventos disponibilizados pela APBDSE foram intensificados a partir do ano de 2004, apresentando em média 02 (dois) cursos por ano, contribuindo para a continuidade da Educação Continuada dos profissionais. No entanto, verifica-se que essa promoção não prioriza a atividade de catalogação, ficando restrita às áreas de gestão e preservação documental. O que nos leva a concluir a necessidade de profissionais e um maior investimento em cursos na área de Organização e Tratamento da Informação, uma vez considerada elemento nuclear da Biblioteconomia.

Quanto aos eventos e cursos de capacitação promovidos pelo Conselho Regional de Biblioteconomia - CRB5, de acordo com os e-mails e documentos (questionários) encaminhados ao presidente, constatou-se que no intervalo dos últimos dez anos, nada acontecera em torno da Educação Continuada, sobretudo, na esfera da Catalogação Descritiva, o que nos leva mais uma vez destacar a participação mais ativa e efetiva dos órgãos de classe, na promoção da Educação Continuada no estado de Sergipe.

\subsection{Forma de análise dos resultados}

O foco temático nessa pesquisa gira em torno da Educação Continuada, sobretudo, àquela voltada para o universo da Catalogação Descritiva. Salienta-se que essa investigação partiu da necessidade emergente de aprimoramento e atualização às atividades bibliotecárias, na qual se buscou traçar um perfil do bibliotecário sergipano e das ações procedidas no estado de Sergipe, nos últimos dez anos. Nessa discussão foi considerada a captação das respostas obtidas na seção anterior, que fundamentam o campo empírico da pesquisa.

Algumas questões foram indagadas, como, por exemplo: Quem são os bibliotecários atuantes em Sergipe? Como o bibliotecário visualiza o exercício da Educação Continuada voltada a atividade de catalogação? Quais são as possibilidades existentes no estado? A catalogação é visualizada como uma atividade de constante aprendizado e reflexão crítica?

Diante dessas indagações a pesquisa resulta no fato de que os bibliotecários sentem necessidade de especialização na Catalogação Descritiva e apontam dificuldades em praticar a Educação Continuada em Sergipe; a maioria dos bibliotecários exerce suas atividades no setor de Organização e Tratamento da Informação e priorizam o uso de padrões. Em relação à promoção da Educação Continuada com o tema Catalogação Descritiva desenvolvida pelos órgãos de classe APBDSE e CRB5 em Sergipe, notou-se a ausência de ações nessa temática. De acordo com os resultados apresentados, aponta-se como uma recomendação que viabilizaria a Educação Continuada no estado de Sergipe a criação de um curso de pós-graduação lato sensu.

\section{Conclusões}

Essa investigação se propôs a apresentar e a discutir sobre a Educação Continuada do bibliotecário/catalogador em ambientes informacionais universitários, localizados em Sergipe. A Catalogação Descritiva é uma das atividades mais clássicas na profissão do bibliotecário, sua realização abarca processos que incluem tecnologias vigentes a cada época, e com constantes atualizações, passando pela revisão dos instrumentos de catalogação a nível internacional, permitindo à padronização mundial da descrição bibliográfica e oportunizando a recuperação da informação de forma mais efetiva ao usuário.

[...] É necessário que o profissional catalogador estenda a sua atuação ampliando também o conceito de catalogação que passa da descrição para a representação de recursos informacionais sempre com vistas às expectativas e necessidades do usuário e a interoperabilidade de todo e qualquer recurso informacional [...] (FUSCO, 2010, p. 230).

Com essa pesquisa conclui-se que a Educação Continuada vem se destacando como uma alternativa eficaz para os bibliotecários manterem o ideal de padronização estabelecido na Catalogação Descritiva, no entanto, verificou-se, que em Sergipe existe a necessidade de ações emergentes de promoção à Educação Continuada por parte das instituições, dos órgãos de classe e dos bibliotecários.

Como ações práticas e respaldadas na literatura científica apresentada nesse trabalho, reforça-se como recomendação a implementação de um curso lato sensu, formatado pelo Núcleo de Ciência da Informação, da Universidade Federal de Sergipe, o qual acampa o curso de Biblioteconomia e Documentação, a fim de subsidiar e 
promover a Educação Continuada dos bibliotecários do estado de Sergipe, oferecendo um amplo espectro de conteúdos aplicados a cada realidade e necessidade informacional.

Espera-se que esse estudo possa contribuir para viabilizar ações de aprendizado contínuo da Catalogação Descritiva em Sergipe, e assim oferecer subsídios para pesquisas futuras nas quais construam formas de debate sobre os "novos rumos da catalogação".

\section{Notas}

1) Catalogação Descritiva ou Representação Descritiva é a terminologia empregada para caracterizar a descrição dos recursos informacionais em ambiente informacionais. (CASTRO, 2008).

2) Para melhor compreensão utilizaremos ao longo do texto a abreviação TIC para nos referirmos as

Tecnologias da Informação e Comunicação.

3) Catalogação Descritiva ou Representação Descritiva é a terminologia empregada para caracterizar a descrição dos recursos bibliográficos em ambientes informacionais, nos seus aspectos de forma e conteúdo. (CASTRO, 2008).

4) A Biblioteca Nacional está localizada no Rio de Janeiro, foi o local responsável pelo primeiro curso de Biblioteconomia no Brasil (1915), dando ênfase ao aspecto cultural na formação bibliotecária. (CASTRO, 2002).

5) De acordo com Machado (2003) o Controle Bibliográfico Universal (CBU), deve ser entendido como um programa de longo alcance contribuindo para uma rede universal de intercâmbio e controle de informações bibliográficas em todos os países.

6) Consideram-se pós-graduações lato sensu os programas de especialização e incluem os cursos designados como MBA - Master Business. Com duração mínima de 360 horas e ao final do curso o aluno obterá certificado e não diploma, ademais são abertos a candidatos diplomados em cursos superiores e que atendam às exigências das instituições de ensino - art. 44, III, Lei oㅜ 9.394/1996. Disponível em: <http://portal.mec.gov.br > Pós-graduação>. Acesso em 15 jan.2012.

7) As pós-graduações stricto sensu compreendem programas de mestrado e doutorado abertos a candidatos diplomados em cursos superiores de graduação e que atendam às exigências das instituições de ensino e ao edital de seleção dos alunos (art. 44, III, Lei no 9.394/1996.). Ao final do curso o aluno obterá diploma. Disponível em: <http://portal.mec.gov.br > Pós-graduação>. Acesso em 15 jan.2012.

8) Conselho de Classe: Órgão representativo da classe profissional atuante no estado no intuito de fiscalizar o exercício da profissão. (PAIXÃO, 2009).

9) Associações: Responsável por congregar profissionais de determinada área, visando atualização e aprimoramento profissional, através da promoção de eventos, cursos, vendas de publicações da área, criação de grupos de trabalho por áreas etc. (PAIXÃO, 2009).

10) Sindicato: Entidade constituída para fins de proteção, estudo e defesa de interesses comuns. (PAIXÃO, 2009).

11) Local em que são realizados a organização e o tratamento da informação que chega à unidade, compreendendo as tarefas de catalogação, classificação e indexação.

12) Refere-se à coordenação e ao gerenciamento das unidades de informação.

13) Setor em que é realizada a interface entre a unidade de informação e o usuário.

14) O PERGAMUM - É um Sistema Integrado de Bibliotecas informatizado de gerenciamento de dados, direcionado aos diversos tipos de Centros de Informação, dentre os seus serviços estão à realização de capacitação e treinamentos. Disponível em: http://www.pergamum.pucpr.br/redepergamum/.Acesso em 22 de set.2012.

15) Manual impresso elaborado pela autora Eliane Serrão Alves Mey (2003), no qual trazem exemplos de forma concisa das regras de catalogação contidas no AACR2.

\section{Bibliografia}

ALMEIDA, Daniela Pereira dos Reis. Proposta de formação em serviço como prática de educação continuada para bibliotecários catalogadores da rede de bibliotecas da UNESP. 2007.130 f. Tese (Doutorado em Ciência da Informação) - Faculdade de Filosofia e Ciências, Universidade Estadual Paulista. Marília, 2007. Disponível em:

$<$ <ttp://www.marilia.unesp.br/Home/Pos.../almeida dpr do mar.pdf>. Acesso em: 18 out. 2012.

ALVES, Rachel Cristina Vesú. Web Semântica: uma análise focada no uso de metadados. 2005.180 f. Dissertação (Mestrado em Ciência da Informação) - Faculdade de Filosofia e Ciências, Universidade Estadual Paulista. Marília, 2005. Disponível em: < http:// www.RCV Alves - 2000, marilia.unesp.br pdf> .Acesso em :24 set. 2012.

Metadados como elementos no processo de catalogação. 2010.134 f. Tese (Doutorado em Ciência da Informação) Faculdade de Filosofia e Ciências, Universidade Estadual Paulista. Marília, 2010. Disponível em: $<$ http://www.marilia.unesp.br/Home/Posgraduacao/Cienciadalnformacao/Dissertacoes/RCV e do mar.pdf> .Acesso em :18 set. 2012.

ASSOCIAÇÃO DOS PROFISSIONAIS BIBLIOTECÁRIOS E DOCUMENTALISTAS DE SERGIPE APBDSE. Estatuto. Aracaju: 2010 , p. 7.

BAPTISTA, Dulce Maria. A catalogação como atividade profissional especializada e objeto de ensino universitário. Revista Informação e Informação, Londrina, v.11, n.1, p.1-12, jan/jun. 2006. Disponível em:

$<$ http:// www.brapci.ufpr.br/index.php?dd60=0\&dd61=catalogacao. htm>. Acesso em: 14 jan.2012. 
BARBOSA, Alice Príncipe. Novos rumos da catalogação. Rio de janeiro: BNG/Brasilart, 1978.

CAMPELLO, Bernadete. Introdução ao controle bibliográfico. 2.ed. Brasília, DF: Briquet de Lemos, 2006.

CASTRO, César Augusto. Histórico e evolução curricular na área de Biblioteconomia no Brasil. In.VALENTIM,Marta Lígia.Formação do profissional da informação. São Paulo: Polis, 2002.

CASTRO, Fabiano Ferreira de. Padrões de representação e descrição de recursos informacionais em bibliotecas digitais na perspectiva da Ciência da Informação:uma abordagem do MarcOnt Initiative na era da Web Semântica. 2008. 201f. Dissertação (Mestrado em Ciência da Informação) - Faculdade de Filosofia e Ciências - Universidade Estadual Paulista, Marília, 2008.

CONSELHO FEDERAL DE BIBLIOTECONOMIA. Disponível em:<http://cfb.org.br>. Acesso em: 10 jan. 2013.

CONSELHO REGIONAL DE BIBLIOTECONOMIA 5푸 região. Disponível em:<http://crb5.org. br>. Acesso em: 15 jan. 2013.

CORRÊA, Elisa Cristina Delfini. Formação do bibliotecário catarinense e as novas tecnologias: contribuição da ACB e do CRB-14. Revista ACB, Santa Catarina, v.6, n.1, p.7-27, 2001. Disponível em:

<http://www. revista.acbsc.org.br/index.php/racb/article/.../358/423.htm>.Acesso em: 29 abr.2012.

CORRÊA, Rosa Maria Rodrigues. Catalogação descritiva no século XXI: um estudo sobre a RDA. 2008.65f. Dissertação (Mestrado em Ciência da informação)- Faculdade de Filosofia e ciências - Universidade Estadual Paulista, Marília.

CRESPO, Isabel Merlo; RODRIGUES, Ana Vera Firnardi; MIRANDA, Celina Leite. Educação continuada para bibliotecários: características e perspectivas em um cenário de mudanças. Biblios, v.7, n.25-26, p.1-14, jul. 2006. Disponível em: <http://www. eprints. rclis.org/8801/1/25 08.pdf>.Acesso em: 29 abr.2012.

I ENACAT e III EEPC, 2012, Rio de Janeiro. Anais eletrônicos...Rio de Janeiro, 2012.Disponível em:<http://www.gepcat.blogspot.com>. Acesso em 21nov.2012.

FEDERAÇÃO BRASILEIRA DE ASSOCIAÇÕES DE BIBLIOTECÁRIOS, CIENTISTAS DA INFORMAÇÃO E INSTITUIÇÕES (FEBAB). Programa de capacitação técnica e gerencial cursos à distância - 2012. São Paulo, 2012. Disponível em <http://www.febab.org.br >. Acesso em: 22 nov.2012.

FUSCO, Elvis. Modelos conceituais de dados como parte do processo da catalogação: perspectiva de uso dos FRBR no desenvolvimento de catálogos bibliográficos digitais. 2010.249 f. Tese (Doutorado em Ciência da Informação) - Faculdade de Filosofia e Ciências, Universidade Estadual Paulista. Marília, 2010. Disponível em: <http://www.marilia.unesp.br/Home/Posgraduacao/Cienciadalnformacao/Dissertacoes/fusco e do mar.pdf> .Acesso em :22 set. 2012.

GIANNASI, Maria Júlia. O profissional da informação diante dosDesafios da sociedade atual: desenvolvimento de pensamento crítico em cursos de educação continuada e a distância via internet, através da metodologia da problematização. 1999.235 f. Tese (Doutorado em Ciência da Informação) - Faculdade de Estudos Sociais Aplicados, Universidade de Brasília. Brasília, 1999. Disponível em: < http://www.uel.br/projetos/eadcin/Produtos/TESE MJ.pdf.>.Acesso em: 14 de nov.2012.

INFORMAR GERÊNCIA DE DOCUMENTAÇÃO E INFORMAÇÃO. Cursos. Disponível em:<http://www.informar-rs.com.br/.> Acesso em: 22 nov. 2012.

MEY, Eliane Serrão Alves; SILVEIRA, Naira Christofoletti. Catalogação no plural. Brasília: Brinquet de Lemos, 2009.

MIRANDA, Antônio L. C. A profissionalização da Ciência da informação no marco da globalização: paradigmas e propostas. In: Nídia M.L. Lubisco; Lídia M.B.Brandão,Salvador (Org.). Informação e informática. Salvador: EDUFBA, 2000.

MIRANDA, Ana Cláudia Carvalho de; SOLINO, Antônia da Silva. Educação continuada e mercado de trabalho: um estudo sobre os bibliotecários do Estado Rio Grande do Norte. Revista Perspectivas em Ciência da Informação, Belo Horizonte, v.11, n.3, p.383397, set/dez. 2006. Disponível em: < http://www.scielo.br/scielo. php?pid=S1413-99362006000300007\&script=sci arttext >. Acesso em: 14 nov.2012

MORENO, Edinei et al. Formação continuada de bibliotecários: análise do conteúdo dos sites das entidades de classe. Revista ACB. Santa Catarina, v.12, n.1, p.43-58, 2007. Disponível em:

$<$ http://periodicos.ufpb.br/ojs/index.php/pbcib/article/view/7065>.Acesso em 30: abr.2012.

MORIGI, José Valdir; PAVAN, Cleusa. Tecnologias de informação e comunicação: novas sociabilidades nas bibliotecas universitárias. Revista Ciência da Informação, Brasília, v.33, n.1, jan./abr., p.117 -125, 2004. Disponível em:

< http://www.scielo.br/pdf/ci/v33n1/v33n1a14.pdf >. Acesso em: 28 abr.2012. 
PEREIRA, Ana Maria; RODRIGUES, Renata. Educação continuada do catalogador: o caso da Universidade do estado de Santa Catarina. Revista ACB. Santa Catarina, v.7, n.1, p.219-239, 2002. Disponível em:

<http://revista.acbsc.org.br/racb/article/view/395>.Acesso em 23: abr.2012.

PEREIRA, Ana Maria; SANTOS, Plácida Leopoldina Ventura Amorim da Costa. Educação continuada na modalidade à distância: uma proposta alternativa. Revista Transinformação Campinas, v.16, n.1, jan./abr., 2004. Disponível em: $<$ http://www.brapci.ufpr.br/index.php?dd60=0\&dd61=catalogacao.htm>Acesso em: mar.2012.

RUCHINSKI, Ana Luiza. Capacitação e atualização do bibliotecário: estudo de caso da Biblioteca Demonstrativa de Brasília. 2009.55f. Monografia (Bacharelado em Biblioteconomia) - Universidade de Brasília, Brasília, 2009. Disponível em: <http://bdm.bce.unb.br/bitstream/.../1/2009 AnaLuizaPereiraRuchinski.pdf.htm>.Acesso em: 15 mar. 2012.

SANTOS, Plácida Leopoldina Ventura Amorim da Costa; CORRÊA, Rosa Maria Rodrigues. Catalogação: trajetória para um código internacional. Niterói: Intertexto, 2009.

SANTOS, Plácida Leopoldina Ventura Amorim da Costa; FLAMINO, Adriana Nascimento. MARC 21 e XML como ferramentas para a consolidação da catalogação cooperativa automatizada: uma revisão de literatura. In: VIDOTTI, Silvana Ap.B. Gregorio (coord.). Tecnologia e conteúdos informacionais: abordagens teóricas e práticas. São Paulo: Polis 2004, 187p. Cap.7, p.113-138.

SANTOS, Sandra Vieira. Educação continuada em catalogação: atualidades e perspectivas dos bibliotecários nas bibliotecas universitárias de Sergipe. 2013. 91f. Trabalho de Conclusão de Curso (Bacharelado em Biblioteconomia) - Universidade Federal de Sergipe, São Cristóvão, 2013.

TARAPANOFF, Kira. Perfil do profissional da informação no Brasil: diagnóstico de necessidade de treinamento e educação continuada. Brasília: IEL/DF, 1997.

\section{Dados dos autores}

\section{Fabiano Ferreira de Castro}

Possui Graduação em Biblioteconomia (2002) pela Universidade Estadual Paulista Júlio de Mesquita Filho, Especialização em Uso Estratégico das Tecnologias em Informação e Comunicação (2006). Mestrado em Ciência da Informação pela Universidade Estadual Paulista Júlio de Mesquita Filho- Campus de Marília (2008). Doutorado em Ciência da Informação (2012) pela UNESP. Atualmente é Professor Adjunto da Universidade Federal de São Carlos (UFSCar) e Líder do Grupo de Pesquisas e Estudos em Representação do Conhecimento e Tecnologias da Informação e Comunicação (GPERTIC).

fabianofcastro.ufs@gmail.com

\section{Sandra Vieira Santos}

Graduada em Biblioteconomia e Documentação pela Universidade Federal de Sergipe - UFS.

sandra.ufs@hotmail.com

Recibido - Received: 2013-08-04

Aceptado - Accepted: 2013-12-30

\section{(c) $)$ EY}

This work is licensed under a Creative Commons Attribution 4.0 United States License.

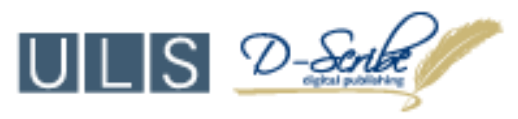

This journal is published by the University Library System of the University of Pittsburgh as part of its D-Scribe Digital Publishing Program and is cosponsored by the University of Pittsburgh Press. 